$\begin{array}{ccc} & \text { ACADEMIA ROMÂNĂ } & \text { Rev. Roum. Chim., } \\ \mathbf{2 0 2 1}, \text { 66(2), 179-183 }\end{array}$

\title{
PROGRAM FOR PREDICTION DIHEDRAL ANGLE FROM VICINAL COUPLING CONSTANT WITH 3-SPHERE APPROACH
}

\author{
Emerich BARTHA, ${ }^{a}$ Carmen-Irena MITAN,,${ }^{\mathrm{a},}$ Constantin DRAGHICI, ${ }^{\mathrm{a}}$ Miron T. CAPROIU, ${ }^{\mathrm{a}}$ Petru FILIP, ${ }^{\mathrm{a}}$ \\ Laszlo TARKO ${ }^{\mathrm{a}}$ and Robert M. MORIARTY ${ }^{\mathrm{b}}$ \\ a Institute of Organic Chemistry “C. D. Nenitescu”, Roumanian Academy, Splaiul Independentei 202B, sect 6, P. P. box 108, \\ Bucharest, 060023, Roumania \\ ${ }^{b}$ University of Illinois at Chicago, Department of Chemistry, Chicago, IL, 60607, U.S.A.
}

Received September 24, 2020

3-Sphere approach is applied on prediction dihedral angle $\theta_{\mathrm{HnHn}+1}[\mathrm{deg}]$ only from vicinal coupling constant ${ }^{3} J_{\mathrm{HnHn+1}}[\mathrm{Hz}]$ with Java script, in comparation with angles calculated from the differences between two atoms of carbon chemical shift $\left(\Delta \delta_{\mathrm{CnCn}+1}[\mathrm{ppm}]\right)$ and Karplus equations. The trigonometric equations 1,2 ensuring the right sign along the D-, L series rule.

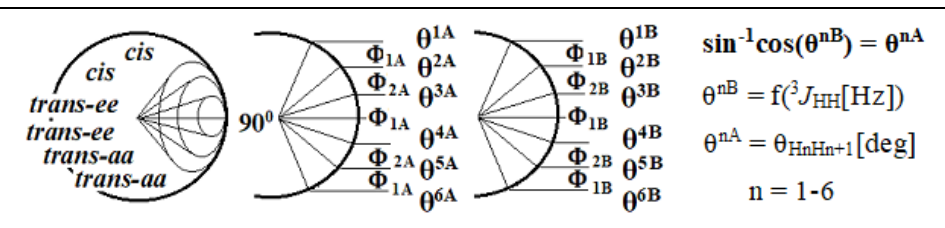

\section{INTRODUCTION}

Karplus is a general method ${ }^{1}$ for the calculation of the dihedral angle $\left(\theta_{\mathrm{HnHn}+1}[\mathrm{deg}]\right)$ from vicinal coupling constant $\left({ }^{3} J_{\mathrm{HnHn}+1}[\mathrm{~Hz}]\right)$ using the valence bond theory, ${ }^{2,3}$ equation optimized and/or particularized by other. ${ }^{4,5}$ The degree of nonplanarity can be determined accurately from knowledge of the torsional angles ${ }^{6}$ using models for pseudorotation. ${ }^{7}$ In this paper we proposed 3 -sphere approach for prediction of the dihedral angles only from vicinal coupling constant with the hypersphere trigonometric eq. 1, equation which gives information about the sign of the predicted dihedral angle, ensuring a good correlation between dihedral angle and vicinal coupling constant.

3-Sphere approach, a method in three steps: 1. Two characteristic angles are calculated from

* Corresponding author: cmitan@yahoo.com
NMR data; 2. Construction of the units with seven sets angles; 3. Calculation of the dihedral angles having right stereochemistry and sign with hypersphere equation. ${ }^{8}$ The higher number of angles under seven set unit rule is drastically reduced with the prediction program.

\section{RESULTS}

Geometric spatial distribution of two protons with cis- or trans-stereochemistry on $\mathrm{HCC}^{\prime} \mathrm{H}^{\prime}$ fragment is represented on three concentric cones, where six possible angles $\left(\theta^{\mathrm{nA}}, \mathrm{n}=1-6\right)$ have two characteristic angles $\phi_{1}$ and $\phi_{2}$, relative to three arbitrary points $\mathrm{P}_{1}-\mathrm{P}_{3}$ (Fig. 1). 3-Sphere is a higher dimensional space, analogue to a sphere with four charts, where each chart is part of the circle to an open interval, and together cover the whole circle. Six dihedral angles can be place in west and east, 
up and down, relative to $+/-90[\mathrm{deg}]$, on three concentric circles, 2D projective plane of 2manifold, occurring twelve positive and negative angles. As going from north to south, values of the torsional angles are placed up on three concentric cones, with angles $2 \mathrm{x} \theta^{\text {cis }}, 2 \mathrm{x} \theta^{\text {cis }}, 2 \mathrm{x} \theta^{\text {trans-ee }}$, and down three concentric cones, with angles $2 \times \theta^{\text {trans-aa }}$, $2 \times \theta^{\text {trans-aa }}, 2 \times \theta^{\text {trans-ee }}$. Three concentric cones having the angle of the first cone $\phi_{1}$, second angle $\phi_{1}+$ $2 \phi_{2}$, and third angle $3 \phi_{1}+2 \phi_{2}$, in east side as well as on west side (Fig. 1), six plus two meridian and longitudinal circles, mimic of the Root systemLie group. ${ }^{9}$

In other representation, in set $A$ are placed angles $\theta^{\mathrm{nA}}$ and in set $\mathrm{B}$ angles half $\phi_{1 \mathrm{~A}}$ and $\phi_{2 \mathrm{~A}}$ of set $A$, namelly $\theta^{\mathrm{nB}}$ of set $B$, with $\mathrm{n}=1-6$. Sets $A$ and $\mathrm{B}$ are in close relationships with set $\mathrm{C}$ through $\phi_{2}$ of set $\mathrm{A}\left(\phi_{2 \mathrm{~A}}=\theta^{1 \mathrm{C}}, \phi_{2 \mathrm{~B}}=\theta^{1 \mathrm{C} \text { or } 2 \mathrm{C}}\right)$. Tessellation of the spherical coordinates $\sin \theta^{\mathrm{nA}}=\mathrm{R}_{\mathrm{m}}=\cos \theta^{\mathrm{nB}}$ leading to the hypersphere trigonometric equation I. Translation from $4 \mathrm{D}$ to $3 \mathrm{D}$ point out through three sets of angles, and hypersphere trigonometric equation. $\mathrm{R}^{4}$ is a complex $\mathrm{C}^{2}$ with Hopf coordinate or quaternion $(\mathrm{H}),{ }^{9}$ Euler's analog.

\section{Eq. $1:^{8} \sin ^{-1}\left(\cos \theta^{\mathrm{nB}}\right)=\theta^{\mathrm{nA}}$,}

where ${ }^{3} J_{\mathrm{HH}}=\mathrm{f}\left(\theta^{\mathrm{nA}}, \phi\right)$ : with $\mathrm{n}=1-6$, and $\phi=$ $\mathrm{f}\left(\phi_{1} / 2, \phi_{2}\right)$, or ${ }^{3} J_{\mathrm{HH}}=\mathrm{f}\left(\theta^{\mathrm{nA}}, \theta^{\mathrm{nB}}\right)$ : with $\mathrm{n}=1-6$, and $\phi=\theta^{\mathrm{nB}} ;$ cis stereochemistry: $\boldsymbol{\theta}^{\mathbf{n B}}=\left(\mathbf{2 x}^{\mathbf{3}} \boldsymbol{J}_{\mathbf{H H}}{ }^{\text {cis }}\right)^{\mathbf{2}}$, trans stereochemistry: $\boldsymbol{\theta}^{\mathrm{nB}}=\left({ }^{3} \boldsymbol{J}_{\mathbf{H H}}{ }^{\text {trans }}\right)^{2}$, and $\theta^{\mathrm{nA}}$ the predicted dihedral angle with right stereochemistry and sign.

In Table 1 are compared dihedral angles of iminocyclitols ${ }^{10} \mathbf{1}, 2$ and $\alpha$-, $\beta$ 5-iodo-methyl-Dribofuranoses $^{11}$ 3a,b (Figure 2), predicted only from ${ }^{3} J_{\mathrm{HnHn}+1}$ with 3 -sphere Java script program, with dihedral angles calculated from the differences between two atoms of carbon chemical shift with hypersphere trigonometric ${ }^{12,13}$ eq. 2 . and Karplus equations ${ }^{2,3,5}$ (K1-K3).

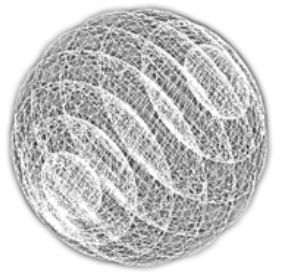

3-Sphere

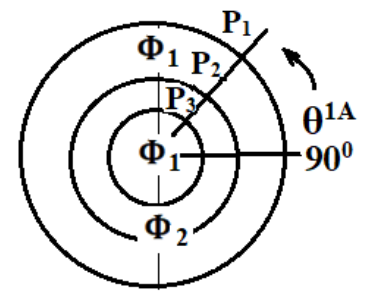

$$
\Phi=f\left(\Phi_{2}, \Phi_{1 / 2}\right)
$$

$$
{ }^{3} J_{\mathrm{HH}}=\mathbf{f}(\Phi)
$$
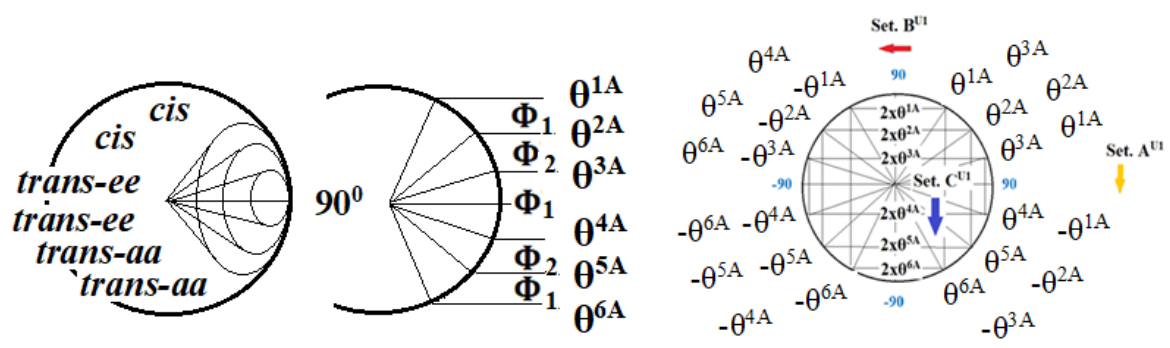

Fig. 1 - Dihedral angles with cis-, trans stereochemistry on 3-sphere and Lie group theories.<smiles>[R][C@]1([2H])N[C@H](CO)[C@@H]2OC(C)(C)O[C@H]21</smiles>

1<smiles>[R]C1([2H])N[C@H](CO)[C@@H](O)[C@@H]1O</smiles>

2<smiles>[R]C[C@H]1O[C@H]([R])[C@@H](O)[C@H]1O</smiles>

$3 a$<smiles>[R]C[C@H]1O[C@H]([R])[C@@H](O)[C@H]1O</smiles>

$3 b$

$$
\mathrm{R}^{1}=\mathrm{CH}_{3}, \mathrm{R}^{2}=\mathrm{I}, \mathrm{R}^{3}=\mathrm{OCH}_{3}
$$

Fig. 2 - Iminocyclitols 1, 2 and $\alpha$-, $\beta$ 5-iodo-methyl-Dribofuranoses 3a,b. 
Table 1

Dihedral angles $\theta^{\mathrm{nA}}[\mathrm{deg}]$ predicted with Java script program in comparation with angles calculated from the differences between two atoms of carbon chemical shifts $\Delta \delta_{\mathrm{CnCn}+1}$ [gauss] and Karplus eq. K1-K3.

\begin{tabular}{|c|c|c|c|c|c|c|c|c|c|}
\hline Entry & $\mathrm{H}_{\mathrm{n}} \mathrm{H}_{\mathrm{n}+1}$ & $\begin{array}{l}{ }^{3} J_{\mathrm{HH}}{ }^{\text {exp }} \\
{[\mathrm{Hz}]^{\mathrm{c}}}\end{array}$ & $\begin{array}{l}\theta^{\mathrm{nB}} \\
{[\mathrm{deg}]^{\mathrm{a}}}\end{array}$ & $\begin{array}{l}\theta^{\mathrm{nA}} \\
{[\mathrm{deg}]^{\mathrm{a}}}\end{array}$ & $\begin{array}{l}\Delta \delta_{\mathrm{CnCn+1}} \\
\text { [gauss] }^{\text {b, c }}\end{array}$ & $\begin{array}{l}\theta_{\mathrm{HH}}^{\text {eq.2 }} \\
{[\mathrm{deg}]}\end{array}$ & $\begin{array}{l}\theta_{\mathrm{HH}}{ }^{\mathrm{K}} \\
{[\mathrm{deg}]}\end{array}$ & $\begin{array}{l}\theta_{\mathrm{HH}}{ }^{\mathrm{K} 2} \\
{[\mathrm{deg}]}\end{array}$ & $\begin{array}{l}\theta_{\mathrm{HH}}{ }^{\mathrm{K} 3} \\
{[\mathrm{deg}]}\end{array}$ \\
\hline 1. & Cis: $\mathrm{H}_{1} \mathrm{H}_{2} \mathbf{1}$ & 4.1 & 67.24 & 22.76 & 0.7759 & $e^{6,1}: 20.88$ & 44.12 & $54.83^{\mathrm{g}}$ & 48.31 \\
\hline 2. & Cis: $\mathrm{H}_{2} \mathrm{H}_{3} \mathbf{1}$ & 5.4 & 116.64 & -26.63 & 0.0224 & $a e^{6,1}:-28.71$ & 35.16 & 59.80 & 37.59 \\
\hline 3. & Trans: $\mathrm{H}_{3} \mathrm{H}_{4} \mathbf{1}$ & $\begin{array}{l}0 \\
0.5 \text { (bs) }\end{array}$ & $\begin{array}{l}0 \\
0.25\end{array}$ & $\begin{array}{l}90.00 \\
90.25\end{array}$ & 0.5154 & $\mathrm{ee}^{4,1}: 91.02$ & $\begin{array}{l}80.11 \\
90 * \text { eq.K1 }\end{array}$ & 75.26 & 69.63 \\
\hline 4. & Cis: $\mathrm{H}_{1} \mathrm{H}_{2} 2$ & 3.1 & 38.44 & 51.55 & 0.3249 & $\mathrm{ae}^{5,2}: 51.73$ & 50.90 & $50.05^{\mathrm{g}}$ & 57.02 \\
\hline 5. & Cis: $\mathrm{H}_{2} \mathrm{H}_{3} 2$ & 3.9 & 60.83 & 29.15 & 0.0560 & $e^{6,1}: 26.78$ & 45.47 & 54.97 & 49.99 \\
\hline 6. & Trans: $\mathrm{H}_{3} \mathrm{H}_{4} 2$ & 8.8 & 77.44 & $-167.4^{\mathrm{g}}$ & 0.1375 & $\mathrm{aa}^{6,1}:-168.9^{\mathrm{g}}$ & 132.13 & 167.70 & 137.7 \\
\hline 7. & Cis: $\mathrm{H}_{1} \mathrm{H}_{2} \mathbf{3 a}^{\mathrm{e}}$ & $3.0^{\mathrm{d}}$ & 36 & 53.99 & 0.8102 & $\mathrm{ea}^{5,2}: 54.24$ & 51.59 & $49.53^{\mathrm{h}}$ & 57.96 \\
\hline 8. & Cis: $\mathrm{H}_{1} \mathrm{H}_{2} \mathbf{3 a}^{\mathrm{f}}$ & $6.0^{\mathrm{d}}$ & 144 & -53.99 & 0.8057 & $\mathrm{ae}^{5,2}:-53.68$ & 30.73 & 57.52 & 32.43 \\
\hline 9. & Trans: $\mathrm{H}_{3} \mathrm{H}_{4} \mathbf{3 b}^{\mathbf{e}}$ & $6.0^{\mathrm{d}}$ & 36 & $-126^{\mathrm{g}, \mathrm{i}}$ & 0.19047 & $\mathrm{aa}^{5,2}:-125.5^{\mathrm{g}}$ & $155.6^{\mathrm{j}}$ & $177.52^{\mathrm{j}}$ & $152.42^{\mathrm{j}}$ \\
\hline
\end{tabular}

a. Bcisd or Btransd, Acisd or Atransd, b. $\Delta \delta_{\mathrm{CnCn}+1}\left[\right.$ gauss] $=0.0280118 \mathrm{x} \Delta \delta_{\mathrm{CnCn}+1}[\mathrm{ppm}]$, c. 1-CDCl $3,2-\mathrm{D}_{2} \mathrm{O},{ }^{3} J_{\mathrm{HH}} 400 \mathrm{MHz}, \delta_{\mathrm{Cn}}$ $75 \mathrm{MHz},{ }^{10}$ d. $3-\mathrm{CDCl}_{3},{ }^{3} J_{\mathrm{HH}} 300 \mathrm{~Hz},{ }^{11}$ e. $\mathrm{PPh}_{3}: \mathrm{I}_{2}:$ imidazole $=2: 1: 2$, HF, reflux, $2 \mathrm{~h}, 48 \%, \alpha: \beta$ 1:5.33, 3:0[Hz], f. $\mathrm{PPh}_{3}: \mathrm{I}_{2}:$ imidazole $=$ 2:1:2, THF, MW, 20min, 17\%, $\alpha: \beta 1.6 .39,6: 0[\mathrm{~Hz}]$, g. sign under D-serie rule, h. trans-ee 3,2 70.46, i. eq. $1: \sin ^{-1} \cos (36)=54$, cis $\rightarrow$ trans: $180-54^{2 \mathrm{~A}}=126^{5 \mathrm{~A}}$, eq. $2: \cos ^{-1} \sin (126)=36,(36)^{2}=6[\mathrm{~Hz}]$, j. trans-aa $a^{6,1}(120+$ cis $)$ or trans-ee $(120-$ cis $)$, instead of trans- $a a^{5,2}$ (probably $180-$ cis).

Eq. $2:^{12,13} \cos ^{-1}\left(\sin \theta^{\mathrm{nA}}\right)=\left(\theta^{\mathrm{nB}}\right)^{1 / 2} / \mathbf{m}={ }^{3} J_{\mathrm{HH}}$, where $\mathrm{m}=2$ cis, $\mathrm{m}=1$ trans,

Eq. K1: ${ }^{2} J_{\mathrm{ab}}=J^{0} \cos ^{2} \theta_{\mathrm{HH}}-0.28\left(0^{0}<\theta_{\mathrm{HH}}<90^{\circ}\right)$, ${ }^{3} J_{\mathrm{ab}}=J^{180} \cos ^{2} \theta_{\mathrm{HH}}-0.28 \quad\left(90^{0}<\theta_{\mathrm{HH}}<180^{\circ}\right)$; ${ }^{3} J_{\mathrm{ab}}=J^{0} \cos ^{2} \theta_{\mathrm{HH}}{ }^{*}$,

Eq. K2: ${ }^{3}{ }^{3} J_{\mathrm{ab}}=1.1+17 \cos ^{2} \theta_{\mathrm{HH}}$, 1.40 .

Eq. K3: ${ }^{5} J_{\mathrm{ab}}=7.76 \cos ^{2} \theta_{\mathrm{HH}}-1.10 \cos \theta_{\mathrm{HH}}+$

\section{DISCUSSION}

Using 3-sphere, a hypersphere in 4dimensional space, and Lie group theories three sets of angles (A, B, C) are comprise on one circle (Fig. 1). The angles of set $\mathrm{A}$ are in close relationships with angles of sets $\mathrm{B}$ and $\mathrm{C}$, since half $\phi_{1 \mathrm{~A}}$ is equal with $\theta_{1 \mathrm{~B}}$ and $\phi_{2 \mathrm{~B}}$ with $\theta_{1 \mathrm{C}}$. Three sets of angles mimic of translation from $4 \mathrm{D}$ to $3 \mathrm{D}$, extended to other two pair of angles giving the unit with seven set angles, with $\theta^{1 \mathrm{~A}}$ and $\theta^{1 \mathrm{~B}}$ equals with $\phi_{2 \mathrm{CA} 1}$ and $\phi_{2 \mathrm{CA} 2}$. The cis-, trans-ee $e^{4,1}$ and trans$a a^{5,2},-a a^{6,1}$ stereochemistry results from seven sets unit and trans-ee $e^{3,2}$ stereochemistry from shadow of seven sets unit, totally 14 sets ensuring the right stereochemistry and sign along trigonometrics equation 1 and 2 (Fig. 3). ${ }^{8}$

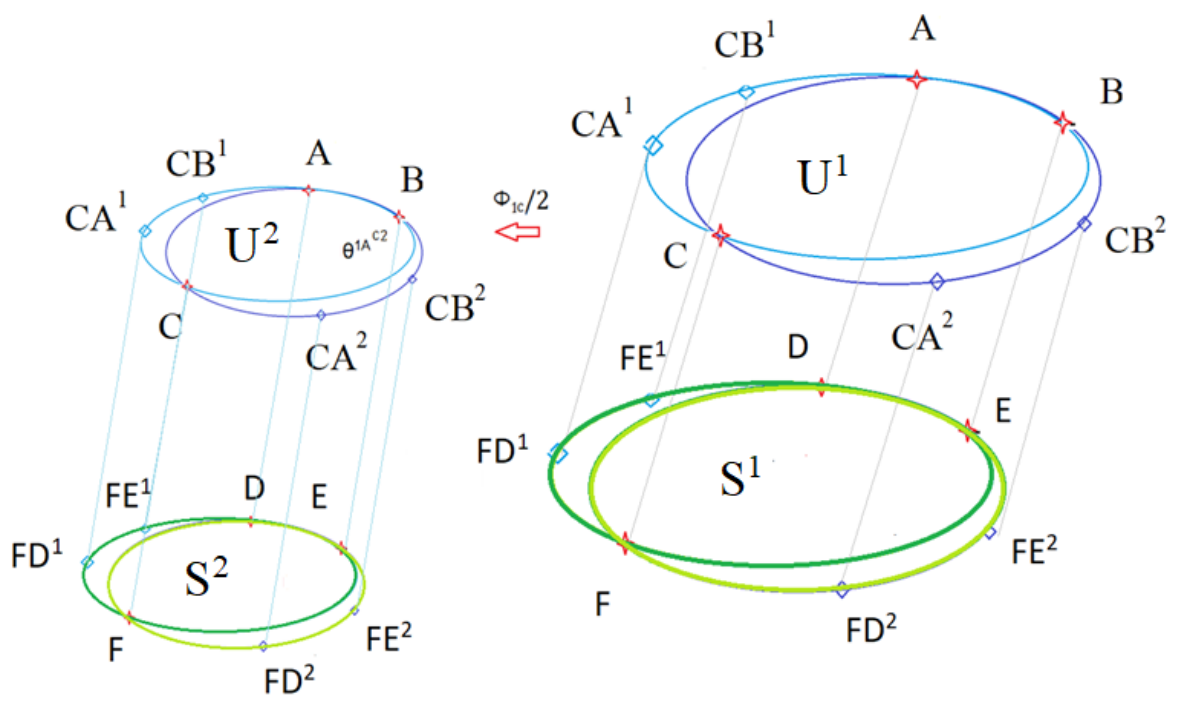

Fig. 3 - Seven sets unit $\left(\mathrm{U}^{\mathrm{N}}\right.$ : A, B, C, CA1, CB1, CA2, CB2)

with coresponding shadow sets $\left(\mathrm{S}^{\mathrm{N}}\right.$ : D, E, F, FD1, FE2, EF1, EF2). 
The number of units can be increased through half $\phi_{1}$ of set $\mathrm{C}$, until the last unit $\left(\mathrm{U}^{\mathrm{N}}\right)$ is almost equal with first unit $\left(\mathrm{U}^{1}\right)$. The shadow sets unit $\left(\mathrm{S}^{\mathrm{N}}\right)$ follow same rule as seven sets unit $\left(\mathrm{U}^{\mathrm{N}}\right)$ or the trans-ee $e^{3,2}$ rule, where the differences between $\phi_{2 \mathrm{~N}}$ and half $\phi_{1 \mathrm{~N}}$ (with $\mathrm{N}$ : A, B, C, CA1, CB1, CA2, CB2) is equal with first angle of coresponding shadow set $\left(\theta^{1 \mathrm{DS}}=\phi_{1 \mathrm{AU}} / 2-\phi_{2 \mathrm{AU}}\right){ }^{8}$

Iminocyclitols ${ }^{10} \mathbf{1 ,} 2$ and $\alpha$-, $\beta$-5-iodo-methylD-ribofuranoses ${ }^{11} \mathbf{3 a , b}$ (Fig. 2) are selected for demonstrating the performaces of the method, since ${ }^{3} J_{\mathrm{HnHn}+1}$ of sugars $\mathbf{1 - 3}$ cover few representative problems: the sign of dihedral angles, the case of vicinal constant couplings of 0 and $8.8[\mathrm{~Hz}]$, and the cis/trans stereochemistry results from ${ }^{3} J_{\mathrm{HnHn}+1}$ of $6[\mathrm{~Hz}]$. Predicted angles only from ${ }^{3} J_{\mathrm{HnHn}+1}[\mathrm{~Hz}]$ have differences of $\sim 2[\mathrm{deg}]$ relative to angles calculated from $\Delta \delta_{\mathrm{CnCn}+1}$ [gauss] (Table 1). The calculated angles are found in unit 1, excepting $\theta_{\mathrm{H} 1 \mathrm{H} 2}(2)$ with $53.78[\mathrm{deg}], 3.03[\mathrm{~Hz}]$ in unit 1 and $51.73[\mathrm{deg}], 3.09[\mathrm{~Hz}]$ in unit $2 .{ }^{8}$

The sign of the dihedral angle predicted with Java script program (Table 1, Entry 1 and 2) is positive for $4.1[\mathrm{~Hz}](22.76[\mathrm{deg}])$ and negative for $5.4[\mathrm{~Hz}](-26.63[\mathrm{deg}])$. Under the $\mathrm{D}$, $-\mathrm{L}$ series rule the sign of $\theta_{\mathrm{H} 3 \mathrm{H} 4}$ is negative, since for positive or negative trans- $a a^{6,1}$ dihedral angle (Table 1, Entry 6 ) with eq. 1 the $\operatorname{sign}^{8}$ is under cylindrical algebraic decomposition algorithm (CAD): $(-\mathrm{X})^{1 / 2}=+/-\mathrm{Y}$, and with eq. 2 for negative angle $(-167.43[\mathrm{deg}]$ trans-a $\left.a a^{6,1}\right)$ the value of the calculated ${ }^{3} J_{\mathrm{HH}}$ increased at $10.25[\mathrm{~Hz}]$, relative to $8.8[\mathrm{~Hz}]$ for positive trans- $a a^{6,1}$ angle.

Two representative values are observed for a vicinal constant coupling of $0[\mathrm{~Hz}], 90$ and $69[\mathrm{deg}]$ (Table 1, Entry 3), the last one calculated with eq. $\mathrm{K} 3$ claim that the $+/-120$ rule between dihedral and trosional angle (trans/cis) must be replaced with "A, B, C sets rule". In this light, eq. K1-K3 for a vicinal constant coupling of $6[\mathrm{~Hz}]$ under 180 rule have the stereochemistry in agreement with trigonometric eq. 2 (Table 1, Entry 9. i.e. $180-$ $57.52=122.48[\mathrm{deg}]$ trans- $a a^{5,2}$ relative to $120+$ $57.52=177.52[\mathrm{deg}]$ trans- $\left.a a^{6,1}\right)$. Under shadow unit rule an angle around $69[\mathrm{deg}]$ in $\mathrm{U}^{1}$ becomes $87[\mathrm{deg}]$ in $\mathrm{S}^{1}\left(\cos ^{-1} \sin \left(\theta^{1 \mathrm{D}}\right)=\theta^{3 \mathrm{~S} 1}, \theta^{1 \mathrm{D}}=\phi_{1 \mathrm{~A}} / 2-\right.$ $\left.\phi_{2 \mathrm{~A}}\right){ }^{8}$ Inadvertence between trans-ee $e^{6,1}$ and trans$e e^{5,3}$ stereochemistry (Table 1, Entry 6) result also with Karplus equations $\mathrm{K} 1-\mathrm{K} 3$ in case of ${ }^{3} J_{\mathrm{HH}}$ $8.8[\mathrm{~Hz}]$. The values of $J_{\text {vic }}$ for $\phi=90^{\circ}$ are very small, and is probably reasonably to ignore the constant of 0.28 in organic chemistry application. ${ }^{14}$
Selective iodination of $\alpha$ - and $\beta$-methyl Dribofuranoses ${ }^{11}(\mathbf{3 a}, \mathbf{b})$, having ratio of anomers $0.50: 0.45$, and coupling constants $\alpha: \beta 3: 0[\mathrm{~Hz}]$, with iodotriphenilphosphonium iodide complex $\left[\mathrm{Ph}_{3} \mathrm{P}+\mathrm{I}-\mathrm{I}-\right]$ generated in situ, gives different vicinal coupling constants: $3: 0[\mathrm{~Hz}]$ under reflux and $6: 0[\mathrm{~Hz}]$ under microwave. Predicted and calculated dihedral angles of $-53.99,-53.68$ [deg] (Table 1, Entry 8) and 126.0, 125.50[deg] (Table 1, Entry 9) with cis or trans stereochemistry results for a vicinal coupling constant of $6[\mathrm{~Hz}]$, relative to positive angles with cis stereochemistry 53.99, $54.24[\mathrm{~Hz}]$ for a vicinal coupling constant of $3[\mathrm{~Hz}]$ (Table 1, entry 7). Cis stereochemistry ${ }^{11}$ was established for ${ }^{3} J_{\mathrm{HH}}$ of $6[\mathrm{~Hz}]$ based on recorded carbon chemical shift $\left(\delta 102^{\alpha}\right.$ and $\left.109^{\beta}[\mathrm{ppm}]\right)$, confirmed by molecular models, in agreement with a good correlation between eq. 1 and eq. 2, out of $+/-120$ rule.

\section{EXPERIMENTAL}

The program for prediction dihedral angle only from recorded ${ }^{3} J_{\mathrm{HnHn}+1}$ with 3 -sphere approach can be obtained from the authors (cmitan@yahoo.com, petrufilip@hotmail.com). Java script code ${ }^{15,16}$ and Notepad++ are used for realization of the program. In the explorer prompt windows (Script Prompt) are introduced the vicinal coupling constants in $\mathrm{Hz}$ for $\mathrm{cis}$ or/and trans stereochemistry, one of them can be omitted, and instead of ${ }^{3} J_{\mathrm{HH}}$ value is write "undefined". Angles Bcisd, Acisd or/and Btransd, Atransd are displayed on webpage, and the alert message Hello World! must be closed. Dihedral angles are Acisd and Atransd[deg], and corresponding vicinal coupling constants $\left({ }^{3} J_{\mathrm{HH}}{ }^{\text {cis }},{ }^{3} J_{\mathrm{HH}}{ }^{\text {trans }}[\mathrm{Hz}]\right)$ results from angles Bcisd and Btransd[deg]. The vicinal coupling constant for trans-ee stereochemistry will be introduced in cis explorer prompt windows.

\section{CONCLUSIONS}

The hypersphere trigonometric equation 1 ensures prediction of the dihedral angles only from vicinal coupling constant with right stereochemistry and sign, two factors with greet importance in calculation of the conformation and configuration. Models for calculation the conformation, the phase angle of the pseudorotation ( $\mathrm{P}[\mathrm{deg}])$ and the angle of deviation from planarity $\left(\theta_{\mathrm{m}}[\mathrm{deg}]\right)$, used three torsional angles or two torsional angles. ${ }^{7}$ The higher number of angles under seven set unit of 3-sphere approach can be reduced with eq. 1 to an approximated value with differences around 2 [deg], following by the identification all the angles with calculated vicinal 
coupling constant almost equal with recorded one in $\mathrm{U}^{\mathrm{N}}(\mathrm{N}=1,2,3, \ldots, \mathrm{n} ; \mathrm{n} \sim 1)$. A program for calculation of the dihedral angles from NMR data with 3-sphere approach is under work. The vicinal coupling constant can be predicted with eq. 2 from dihedral angle obtained from X-ray or other method.

\section{REFERENCES}

1. B. Coxon, Adv. Carb. Chem. Biochem. 2009, 62, 17, doi.org./10.1016/50065-2318(09)00003-1.

2. M. Karplus J. Chem. Phys. 1959, 30, 11, doi.org/10.1063/1.1729943.

3. M. Barfield, M. Karplus, J. Am. Chem. Soc. 1969, 91, 1, doi.org/10.1021/ja01029a001.

4. K. G. R. Pachler, J. Chem. Soc., Perkin Trans II, 1972, 1936, doi.org/10.1039/P29720001936.

5. C. A. G. Haasnoot, F. A. A. M. deLeeuw and C. Altona, Tetrahedron, 1980, 36, 2783, doi.org/10.1016/00404020(80)80155-4.

6. J. B. Houseknecht, C. Altona, C. M. Hadad and T. L. Lowary, J. Org. Chem., 2002, 67, 4647, doi.org/10.1021/jo025635q.

7. H. A. Taha, M. R. Richards and T. L. Lowary, Chem. Rev., 2013, 113, 1851, doi.10.1021/cr300279n.
8. C.-I. Mitan, E. Bartha, C. Draghici, M. T. Caproiu, P. Filip, L. Tarko and R. M. Moriarty, ACS VIRTUAL National Meeting 17-20 August, 2020, Oral Anyl 22, doi.10.1021/scimeetings.Oc06576.

9. Wikipedia, https://en.wikipedia.org/wiki/3-sphere, Lie algebra, Hopf coordinates.

10. R. M. Moriarty, C. I. Mitan, N. Branza-Nichita, K. R. Phares and D. Parrish, Org. Lett. 2006, 8, 3465, doi.org/10.1021/ol061071r.

11. C.-I. Mitan, E. Bartha, A. Hartopeanu, C. Stavarache, C. Draghici, M. T. Caproiu, M. Manganu, I. Man, L. Tarko, F. Teodorescu and C. Deleanu, ACS VIRTUAL National Meeting 17-20 August, 2020, poster Anyl 49, doi.10.1021/scimeetings.Oc00571.

12. C.-I. Mitan, E. Bartha, P. Filip, C. Draghici, M. T. Caproiu and R. M. Moriarty, ACS National Meeting in Orlando, Florida, 31 March-4 April, 2019, Oral Anyl 392, Sci-Mix Anyl 392.

13. C.-I. Mitan, P. Filip, C. Deleanu, R. M. Moriarty, C. Draghici, M. T. Caproiu and E. Bartha, ACS National Meeting in Orlando, Florida, 31 March-4 April, 2019, poster, Anyl 172.

14. S. Sternhell, Q. Rev. Chem. Soc., 1969, 23, 236, Doi: 10.1039/QR 9692300236.

15. G. Perry, D. Miller, Beginning Programming, Third edition, SAMS Teach Yourself, Indianapolis, Indiana, 46240 USA.

16. W3schols.com, http://www.w3schools.com, HTML, CSS, Java Script. 
